\title{
OPTIMIZATION OF TOURISTANT ASV WITH JACOBIAN APPROACH
}

\author{
Teguh Herlambang ${ }^{1}$, Diecky Adzkiya ${ }^{2}$, , Hendro Nurhadi ${ }^{3,4}$ \\ ${ }^{1}$ Information System Department - University of Nahdlatul Ulama Surabaya (UNUSA) \\ teguh@unusa.ac.id \\ ${ }^{2}$ Department of Mathematics, FMKSD ITS, Indonesia \\ dieky@matematika.its.ac.id \\ ${ }^{3}$ Department of Mechanical Engineering, Vocational Faculty, ITS, Indonesia \\ ${ }^{4}$ Center of Excellence for Mechatronics Industrial Automation (PUI-PT MIA-RC \\ hdnurhadi@me.its.ac.id
}

\begin{abstract}
An Autonomous Surface Vehicle (ASV) is an unmanned ship that can automatically navigate itself in watery area. ASV can be utilized as tourism modes, transportation modes, Indonesian military (TNI) fleets or warships. In this paper, the study used a Touristant ASV prototype with a length of 3 meters, a diameter of 1.5 meters, and a height of 1.3 meters. The ASV motion system is a linear model with 3-DOF (surge, sway and yaw), resulted from the linearization of the ASV nonlinear model into a linear model which, then, was optimized as the basis of the navigation and guidance control system. The objective of this paper is to check the controllability and observability of the ASV Touristant linear model. The contribution of this paper is to provide numeric study on the controllability and observability of the model.
\end{abstract}

Keyword: ASV, 3-DOF, linear model, Optimization, Controlable, Observable

\section{INTRODUCTION}

Indonesia is a country with a large watery area of about two thirds of the country's total territory $[1,2]$. Therefore, the country requires a multifunctional vehicle that can be utilized for a transportation mode, a mode of tourism, and a maritime defense system [3]. One of the multifunctional vehicles is the Autonomous Surface Vehicle (ASV). ASV is an unmanned ship that can automatically navigate itself in the waters. Since the ASV does not have a crew on it, a control system is needed. Before the control system is simulated, the system must be optimized first to find out the nature of its controllability and observability [4].

In this paper, the study used an ASV Touristant prototype with a length of 3 meters, a diameter of 1.5 meters, and a height of 1.3 meters, and the ASV Touristant can carry 2 up to 3 people, making it quite adequate as a tourism mode or a vessel for border areas monitoring. The model used was a linear model resulting from the linearization of the non-linear model. The linear model was hypothesized that the nature of its controllability and observability is the basis of the navigation and guidance control system.

\section{MATERIAL / METHODOLOGY}

\subsection{Autonomous Surface Vehicle}

ASV has GPS (Global Positioning System), sensors, gas, $\mathrm{pH}$ sensors, bluetooth, and telemetry installed. The ship automatically moves to the determined location in realtime. ASV can be used, other than as a research vessel, for a survey ship, inspection of river conditions, seismic surveys, rescue operations and the like. The profile and specifications of TOURISTANT ASV are as shown in Figure 2.1 and Table 2.1. 


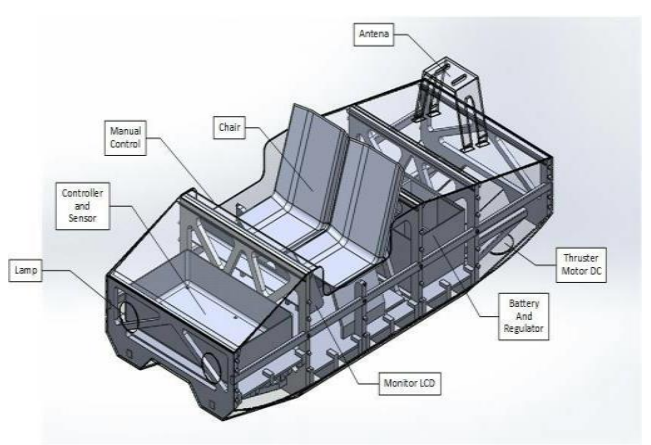

FIGURE 2.1. Profile of Touristant ASV

TABLE 2.1. Specification of Touristant ASV

\begin{tabular}{|l|l|}
\hline Length & $4.12 \mathrm{~m}$ \\
\hline Bean & $1.625 \mathrm{~m}$ \\
\hline Depth & $1.027 \mathrm{~m}$ \\
\hline DWL & $0.3 \mathrm{~m}$ \\
\hline AP & $-2.618 \mathrm{~m}$ \\
\hline FP & $2.618 \mathrm{~m}$ \\
\hline
\end{tabular}

The study used the equation of ship motion with 3 degrees of freedom from 6 degrees of freedom namely surge, sway and, yaw. In general, the ship motions are divided into two types, that is, translational and rotational motions. Translational motion is divided into three, that is, surge, sway and heave. While rotational motion is divided into three, that is roll, pitch, and yaw [5].

By using a simplified nonlinear model [5]:

\section{Surge}

study, the external interference or

environmental factors are considered as the force against wind speed and that against wave height and moment of wind speed and force against wave height. So, the equations are as follows:

$$
\begin{gathered}
X_{\text {ext }}=X_{\text {wind }}+X_{\text {waves }} \\
Y_{\text {ext }}=Y_{\text {wind }}+Y_{\text {waves }} \\
N_{\text {ext }}=N_{\text {wind }}+N_{\text {waves }}
\end{gathered}
$$

From the description of $X_{\text {ext }}, Y_{\text {ext }}$ and $N_{\text {ext }}$, nonlinear equation is obtained as follows.

\section{Surge}

$\left(m-X_{\dot{u}}\right) \dot{u}=X_{|u| u}|u| u+(1-h) X_{\text {prop }}+\left(m+X_{v r}\right) v r+\left(m x_{G}+\right.$

\section{Sway}

$\left(m-Y_{\dot{v}}\right) \dot{v}+\left(m x_{G}-Y_{\dot{r}}\right) \dot{r}=-\left(m-Y_{u r}\right) u r+Y_{u v} u v+Y_{|v| v}|v| v+$

Yaw

$\left(m x_{G}-N_{\dot{v}}\right) \dot{v}+\left(I_{z}-N_{\dot{r}}\right) \dot{r}=-\left(m x_{G}-N_{u r}\right) u r+N_{u v} u v+N_{|v| v \mid}|v|$

Then supposed as follows:

$U_{\text {surge }}=X_{|u| u}|u| u+\left(m+X_{v r}\right) v r+\left(m X_{G}+\right.$ $\left.X_{r r}\right) r^{2}+X_{\delta \delta} \delta^{2}+X_{\text {wind }}+X_{\text {waves }}$

(4)

$V_{s w a y}=-\left(m-Y_{u r}\right) u r+Y_{u v} u v+Y_{|v| v}|v| v+$ $Y_{|v| r}|v| r+Y_{\text {wind }}+Y_{\text {waves }}$

(5)

$$
N_{\text {yaw }}=-\left(m X_{G}-N_{u r}\right) u r+
$$

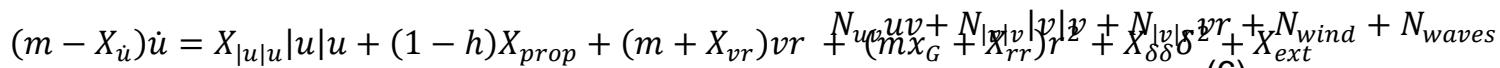

Sway

From the above examples of $U_{\text {surge }}, V_{\text {sway }}$

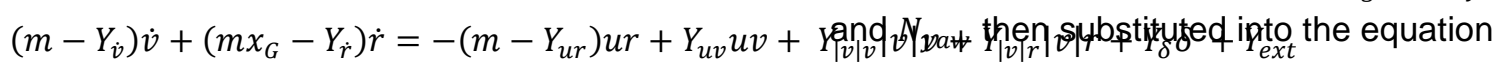

$$
(4-6) \text {, Thus, }
$$

Yaw

$$
\left(m-X_{\dot{u}}\right) \dot{u}=(1-h) X_{\text {prop }}+
$$

$\left(m x_{G}-N_{\dot{v}}\right) \dot{v}+\left(I_{z}-N_{\dot{r}}\right) \dot{r}=-\left(m x_{G}-N_{u r}\right) u r+N_{u v} u v_{\text {surg }}^{+} N_{|q| v \mid v}|v| v+N_{|v| r} v r+N_{\delta} \delta+N_{e x t}$

From the above equation, what is meant

by $X_{\text {ext }}, Y_{\text {ext }}$ and $N_{\text {ext }}$ is external interference

to the motion of surge, sway and yaw. In this 
$\left(m-Y_{\dot{v}}\right) \dot{v}+\left(m X_{G}-Y_{\dot{r}}\right) \dot{r}=Y_{\delta} \delta+$
$V_{\text {sway }}$

$\left(m X_{G}-N_{\dot{v}}\right) \dot{v}+\left(I_{z}-N_{\dot{r}}\right) \dot{r}=N_{\delta} \delta+$ $N_{\text {yaw }}$

From the equations $(7-8)$ they are formed into state space $\dot{\mathrm{u}}, \dot{\mathrm{v}}$ dan $\dot{\mathrm{r}}$, so that:

Surge

$\dot{u}=T_{1}\left((1-t) X_{\text {prop }}+U_{\text {surge }}\right)$

\section{Sway}

$\dot{\mathrm{V}}=\mathrm{T}_{2}\left(\mathrm{Y}_{\delta} \delta_{1}+\mathrm{V}_{\text {sway }}\right)+\mathrm{T}_{3}\left(\mathrm{~N}_{\delta} \delta_{1}+\mathrm{N}_{\text {yaw }}\right)$

Yaw

$\dot{\mathrm{r}}=\mathrm{T}_{4}\left(\mathrm{Y}_{\delta} \delta_{2}+\mathrm{V}_{\text {sway }}\right)+\mathrm{T}_{5}\left(\mathrm{~N}_{\delta} \delta_{2}+\mathrm{N}_{\text {yaw }}\right)$

The expected linear model is obtained as follows:

$$
\begin{aligned}
& \dot{x}(t)=A x(t)+B u(t) \\
& y(t)=C x(t)+D u(t)
\end{aligned}
$$

To determine $\dot{x}(t)$, the matrix of Jacobi is formed as follows:

$J_{x 1}=\left[\begin{array}{lll}\frac{\partial \Sigma_{X}}{\partial u} & \frac{\partial \Sigma_{X}}{\partial v} & \frac{\partial \Sigma_{X}}{\partial r} \\ \frac{\partial \Sigma_{Y}}{\partial u} & \frac{\partial \Sigma_{Y}}{\partial v} & \frac{\partial \Sigma_{Y}}{\partial r} \\ \frac{\partial \Sigma_{N}}{\partial u} & \frac{\partial \Sigma_{N}}{\partial v} & \frac{\partial \Sigma_{N}}{\partial r}\end{array}\right]$

From the above differential derivation, the following is obtained.

$A=J_{x 2}=\left[\begin{array}{ccc}T_{1} & 0 & 0 \\ 0 & T_{2} & T_{3} \\ 0 & T_{4} & T_{5}\end{array}\right] J_{x 1}$
$A=J_{x 2}=\left[\begin{array}{lll}a_{11} & a_{12} & a_{13} \\ b_{21} & b_{22} & b_{23} \\ c_{31} & c_{32} & c_{33}\end{array}\right]$

In which,

$$
\begin{aligned}
& a_{11}=T_{1} 2 \bar{u} X_{|u| u} \\
& a_{12}=T_{1} \bar{r}\left(m+X_{v r}\right) \\
& a_{13}=T_{1}\left(\left(m+X_{v r}\right) \bar{v}+2 \bar{r}\left(m x_{G}\right.\right. \\
& \left.\left.+X_{r r}\right)\right) \\
& b_{21}=T_{2}\left(-\bar{r}\left(m-Y_{u r}\right)+Y_{u v} \bar{v}\right) \\
& +T_{3}\left(-\bar{r}\left(m x_{G}\right.\right. \\
& \left.\left.-N_{u r}\right)+\bar{v} N_{u v}\right) \\
& b_{22}=T_{2}\left(\bar{u} Y_{u v}+2 \bar{v} Y_{|v| v}+\bar{r} Y_{|v| r}\right)+T_{3}(: \\
& +2 \bar{v} N_{|v| v}+\bar{r} N_{|v|} \\
& b_{23}=T_{2}\left(-\bar{u}\left(m-Y_{u r}\right)+\bar{v} Y_{|v| r}\right) \\
& +T_{3}\left(-\bar{u}\left(m x_{G}\right.\right. \\
& \left.-N_{u r}\right) \\
& \left.+\bar{v} N_{|v| r}\right) \\
& c_{31}=T_{4}\left(-\bar{r}\left(m-Y_{u r}\right)+Y_{u v} \bar{v}\right) \\
& +T_{5}\left(-\bar{r}\left(m x_{G}\right.\right. \\
& \left.\left.-N_{u r}\right)+\bar{v} N_{u v}\right) \\
& c_{32}=T_{4}\left(\bar{u} Y_{u v}+2 \bar{v} Y_{|v| v}+\bar{r} Y_{|v| r}\right) \\
& +T_{5}\left(\bar{u} N_{u v}\right. \\
& +2 \bar{v} N_{|v| v} \\
& \left.+\bar{r} N_{|v| r}\right) \\
& c_{33}=T_{4}\left(-\bar{u}\left(m-Y_{u r}\right)+\bar{v} Y_{|v| r}\right) \\
& +T_{5}\left(-\bar{u}\left(m x_{G}\right.\right. \\
& \left.-N_{u r}\right) \\
& \left.+\bar{v} N_{|v| r}\right)
\end{aligned}
$$

Then, for the Jacobi Matrixes Control, partial derivation is done as follows.

$$
J_{u 1}=\left[\begin{array}{lll}
\frac{\partial \Sigma_{X}}{\partial X_{\text {prop }}} & \frac{\partial \Sigma_{X}}{\partial \delta} & \frac{\partial \Sigma_{X}}{\partial \delta} \\
\frac{\partial \Sigma_{Y}}{\partial X_{\text {prop }}} & \frac{\partial \Sigma_{Y}}{\partial \delta} & \frac{\partial \Sigma_{Y}}{\partial \delta} \\
\frac{\partial \Sigma_{N}}{\partial X_{\text {prop }}} & \frac{\partial \Sigma_{N}}{\partial \delta} & \frac{\partial \Sigma_{N}}{\partial \delta}
\end{array}\right]
$$

Then $J_{x 2}$ is obtained as follows. 
Thus, the Jacobi Matrixes Control is as follows.

$B=J_{u 2}=\left[\begin{array}{ccc}T_{1} & 0 & 0 \\ 0 & T_{2} & T_{3} \\ 0 & T_{4} & T_{5}\end{array}\right] J_{u 1}$

$B=J_{u 2}=\left[\begin{array}{ccc}A_{11} & 0 & 0 \\ 0 & B_{22} & B_{23} \\ 0 & C_{32} & C_{33}\end{array}\right]$

In which,

$$
\begin{aligned}
& A_{11}=T_{1}(1-h) \\
& B_{22}=T_{2} Y_{\delta}+T_{3} N_{\delta} \\
& B_{23}=T_{2} Y_{\delta}+T_{3} N_{\delta} \\
& C_{32}=T_{4} Y_{\delta}+T_{5} N_{\delta} \\
& C_{33}=T_{4} Y_{\delta}+T_{5} N_{\delta}
\end{aligned}
$$

So that the result of the linearization from nonlinear model is as follows.

$\left[\begin{array}{c}\dot{u} \\ \dot{v} \\ \dot{r}\end{array}\right]=J_{x 2}\left[\begin{array}{c}u \\ v \\ r\end{array}\right]+J_{u 2}\left[\begin{array}{c}X_{\text {prop }} \\ \delta \\ \delta\end{array}\right]$

$$
\begin{aligned}
& {\left[\begin{array}{c}
\dot{u} \\
\dot{v} \\
\dot{r}
\end{array}\right]=\left[\begin{array}{lll}
a_{11} & a_{12} & a_{13} \\
b_{21} & b_{22} & b_{23} \\
c_{31} & c_{32} & c_{33}
\end{array}\right]\left[\begin{array}{l}
u \\
v \\
r
\end{array}\right]+} \\
& {\left[\begin{array}{ccc}
A_{11} & 0 & 0 \\
0 & B_{22} & B_{23} \\
0 & C_{32} & C_{33}
\end{array}\right]\left[\begin{array}{c}
X_{\text {prop }} \\
\delta \\
\delta
\end{array}\right]}
\end{aligned}
$$

From equation (19) to distinguish sway and yaw control motion so $\delta$ will be defined $\delta_{1}$ and $\delta_{2}$ for yaw

$$
\begin{gathered}
\dot{u}=a_{11} u+a_{12} v+a_{13} r+A_{11} X_{\text {prop }} \\
\dot{v}=b_{21} u+b_{22} v+b_{23} r+B_{22} \delta_{1} \\
+B_{23} \delta_{1} \\
\dot{r}=c_{31} u+c_{32} v+c_{33} r+C_{32} \delta_{2} \\
+C_{33} \delta_{2}
\end{gathered}
$$

To determine $y(t)$ can be taken $\mathrm{C}$ as indentity matrix and $D=0$.

\section{Controllability and Observability}

The system is said to be controllable if the matrix control rank is the same as the dimensions of the controllability matrix system that is formed from matrix $A$ and matrix $\mathrm{B}$. The controllability matrix is as follows:

Controlable $=\left(B|A B| A^{2} B|\ldots| A^{n-1} B\right)$

The dimensions of the system is $n=3$, so that it is

$$
\text { Controlable }=\left(B|A B| A^{2} B \mid A^{2} B\right)=3
$$

So, the system is controllable because it has rank $=3$

The system is said to be controllable if its observability rank has the same dimension as the system does. The observability matrix is formed of matrix $A$ and matrix $C$, in which the observability matrix is as follows.

Observable $=\left(\begin{array}{c}C \\ C A \\ C A^{2} \\ \vdots \\ C A^{n-1}\end{array}\right)$

The dimensions of the system is $n=3$, so that it is

Observable $=\left(\begin{array}{c}C \\ C A \\ C A^{2}\end{array}\right)$

So that the system is observable because it has rank $=3$

\section{CONCLUSION}

Based on the Jacobian analysis, the controllability and observability of the Touristant ASV system is confirmed. And, the linearization of nonlinear ASV system can produce controllable and observable linear ASV system. Then, after the nature of the controllability and observability of the linear system of ASV, the model can be applied to navigation and guidance control system

\section{REFERENCES}

[1]. Herlambang, T., Nurhadi $\mathrm{H}$ and Subchan, 2014. Preliminary Numerical Study on Designing Navigation and 
Stability Control Systems for ITS AUV, Applied Mechanics and Materials Vol. 493 (2014) pp 420-425 Trans Tech Publications, Switzerland.

[2]. Herlambang, T., Djatmiko E.B and Nurhadi H., 2015, "Navigation and Guidance Control System of AUV with Trajectory Estimation of Linear Modelling", Proc. of International Conference on Advance Mechatronics, Intelligent Manufactre, and Industrial Automation, IEEE , ICAMIMIA 2015,Surabaya, Indonesia, pp. 184-187, Oct $15-17$.

[3]. Herlambang, T., Djatmiko E.B and Nurhadi H., 2015, "Ensemble Kalman Filter with a Square Root Scheme (EnKFSR) for Trajectory Estimation of AUV SEGOROGENI ITS", International Review of Mechanical Engineering IREME Journal, Vol. 9, No. 6. Pp. 553560, ISSN 1970 - 8734. Nov.

[4]. Oktafianto, K., Herlambang T., Mardlijah, Nurhadi H., 2015, "Design of Autonomous Underwater Vehcle Motion Control Using Sliding Mode Control Method", International Conference on Advance Mechatronics, Intelligent Manufactre, and Industrial Automation (ICAMIMIA)-IEEE Surabaya Indonesia, 15 - 16 Oktober 2015.

[5]. Fossen, T.I. 1994. Guidance and Control of Ocean Vehicles. Hoboken :Wiley. 